\title{
The Early Maturation of Visual Cortical Area MT is Dependent on Input from the Retinorecipient Medial Portion of the Inferior Pulvinar
}

\author{
Claire E. Warner, William C. Kwan, and James A. Bourne \\ Australian Regenerative Medicine Institute, Monash University, Clayton, 3800 Victoria, Australia
}

The hierarchical development of the primate visual cortex and associated streams remains somewhat of a mystery. While anatomical, physiological, and psychological studies have demonstrated the early maturation of the dorsal "where"/"how" or motion cortical stream, little is known about the circuitry responsible. The influence of the retinogeniculostriate pathway has been investigated, but little attention has been paid to the role of two more recently described disynaptic retinothalamic projections to the middle temporal (MT) area, an early maturing dorsal stream cortical field, and which bypass the primary visual cortex (V1). These pathways are via the koniocellular layers of the lateral geniculate nucleus (LGN) and the medial portion of the inferior pulvinar (PIm). Both have been demonstrated in the adult nonhuman primate, but their influence during the maturation of the visual cortex is unknown. We used a combination of neural tracing and immunohistochemistry to follow the development of LGN and PIm inputs to area MT in the marmoset monkey. Our results revealed that the early maturation of area MT is likely due to the disynaptic retinopulvinar input and not the retinogeniculate input or the direct projection from V1. Furthermore, from soon after birth to adulthood, there was a dynamic shift in the ratio of input from these three structures to area MT, with an increasing dominance of the direct $\mathrm{V} 1$ afference.

\section{Introduction}

The parallel processing of visual information through the dorsal and ventral streams of the primate visual cortex has long been argued on the basis of their distinct processing features (Ungerleider and Mishkin, 1982; Goodale and Milner, 1992; Milner and Goodale, 2008) and developmental trajectory (Bourne, 2010). Anatomical, physiological, and cognitive studies clearly demonstrate that the dorsal "where"/"how" or motion stream and associated areas develop and mature before the ventral "what" or object stream associated cortices (Gogtay et al., 2004; Bourne, 2010; Wattam-Bell et al., 2010; Kiorpes et al., 2012). Further evidence for both the independent development profile of these two pathways can be extrapolated from the early maturation of the dorsal stream-associated middle temporal (MT) area (V5) before any other visual association area (Condé et al., 1996; Bourne and Rosa, 2006). This led to the conclusion that area MT may be acting as a primary-like area in addition to the primary visual

Received July 9, 2012; revised Aug. 25, 2012; accepted Sept. 22, 2012.

Author contributions: C.E.W. and J.A.B. designed research; C.E.W., W.C.K., and J.A.B. performed research;C.E.W. and J.A.B. analyzed data; C.E.W. and J.A.B. wrote the paper.

This work was supported by National Health and Medical Research Council Project Grant APP1002051 and an R. D. Wright Fellowship (J.A.B.). The Australian Regenerative Medicine Institute is supported by grants from the State Government of Victoria and the Australian Government. We thank Professors David Leopold and Anita Hendrickson for their insightful comments that improved this manuscript, and Dr. Baki Billah (Department of Epidemiology and Preventive Medicine, Monash University, Victoria, Australia) for assistance with statistical analyses.

Correspondence should be addressed to Dr. James Bourne, Australian Regenerative Medicine Institute, Level 1 North, Building 75 (STRIP 1), Monash University, Clayton, 3800 Victoria, Australia. E-mail: james. bourne@monash.edu.

DOI:10.1523/JNEUROSCI.3269-12.2012

Copyright $\odot 2012$ the authors $\quad 0270-6474 / 12 / 3217073-13 \$ 15.00 / 0$ cortex (V1) (Bourne and Rosa, 2006), with each area acting as an organizational node and independently subserving the development of the two streams. This view is necessarily speculative since few studies to date have focused on the differential development of direct and indirect anatomical pathways that carry visual information to area MT.

The early cellular maturation of area MT has a temporal sequence similar to V1 (Bourne and Rosa, 2006), suggesting that the development of area MT may involve its direct connectivity with dorsal visual thalamic nuclei, rather than its direct connection with V1 (Nassi and Callaway, 2006). The previously described retinofugal pathways to area MT via the koniocellular (K) layer of the lateral geniculate nucleus (LGN) (Sincich et al., 2004) and medial portion of the inferior pulvinar nucleus (PIm) (Sincich et al., 2004; Lyon et al., 2010; Warner et al., 2010) are likely candidates (Fig. 1). An exuberance of retinal connections during development could significantly influence the early maturation of area MT (Labar et al., 1981). The early establishment of area MT (Fig. 1) could then serve as an important determinant for the layout of the dorsal stream associated extrastriate areas, with which it has direct connectivity (Maunsell and van Essen, 1983; Weller et al., 1984; Ungerleider and Desimone, 1986; Krubitzer and Kaas, 1990; Felleman and van Essen, 1991). For example, a strong connectivity exists between area MT and the dorsal medial area, an area that matures soon after area MT (Bourne, 2010).

In the present study we explored the developmental time course of anatomical pathways through the dorsal visual thalamus carrying retinal information to area MT in the postnatal 
marmoset monkey. We performed a combination of anterograde and retrograde anatomical tracing and immunocytochemical labeling of functional markers in animals ranging from soon after birth to adulthood. Incorporating a novel analysis method, we estimated the viability of the V1-bypassing pathways to area MT from early in postnatal life to adulthood. With this approach, we established shortly after birth that the retinopulvinar (PIm) input to area MT was much greater than the direct projection from V1, but then decreased as the direct V1 projection increased. This suggests a significant role for the medial portion of the inferior pulvinar nucleus in the early development of visual cortical area MT.

\section{Materials and Methods}

Animals. A total of $36 \mathrm{New}$ World marmoset monkeys (Callithrix jacchus) of either sex, ranging from postnatal day $0(\mathrm{P} 0)$ to adult were used in the present study. Thirteen were used for fluorescent tracer injections, and two of these (P14 and adult) also underwent light deprivation/activation protocol for examination of cFos expression (see below). An additional 23 were used specifically for immunohistochemistry, of which 13 had been used in previous studies (Bourne and Rosa, 2006; Bourne et al., 2007). See Table 1 for specific animals for each component of the study. All experiments were conducted in accordance with the Australian Code of Practice for the Care and Use of Animals for Scientific Purposes and were approved by the Monash University Animal Ethics Committee, which also monitored the welfare of these animals.

Procedures. Animals younger than P60 were anesthetized with isoflurane $(1-2 \%$ in $0.5 \mathrm{~L} \cdot \min ^{-1}$ medical oxygen), whereas older animals were initially anesthetized with intramuscular injections of Alfaxan $\left(8 \mathrm{mg} \cdot \mathrm{kg}^{-1}\right)$ and diazepam $\left(3.0 \mathrm{mg} \cdot \mathrm{kg}^{-1}\right)$. Once anesthetized, all animals were administered antibiotic (procaine penicillin, $25 \mathrm{mg} \cdot \mathrm{kg}^{-1}$, i.m.) and placed in a stereotaxic frame on a thermostatically controlled heating pad to maintain core body temperature at $38^{\circ} \mathrm{C}$. For all animals, anesthesia was maintained with isoflurane $\left(1-2 \%\right.$ in $0.5 \mathrm{~L} \cdot \mathrm{min}^{-1}$ medical oxygen). Surgeries were performed under aseptic conditions and blood oxygen levels, heart rate, and temperature were monitored continuously throughout the experiment (Surgivet Advisor Vital Signs Monitor).

Our protocol for neural tracing was described previously (Warner et al., 2010). In brief, for intraocular injection, retinal ganglion cells were labeled by a $1 \%$ solution of Cholera toxin subunit $\mathrm{b}(\mathrm{CTb})$ conjugated with fluorescent tracer Alexa Fluor 488 (CTb-AF488; Invitrogen). Tracer was injected (5-8 $\mu$ l over 3-5 min) into the vitreous of the right eye using a glass micropipette attached to a $10 \mu$ l Hamilton microsyringe (see Fig. 2).

For cortical injection, a craniotomy was made over area MT of the left hemisphere, and the dura was resected. This window was large enough to visualize the lateral sulcus (LS) and the dorsal extent of the superior temporal sulcus (STS) so that the location of area MT could be determined. Using the LS and STS as landmarks the retrograde fluorescent tracer fast blue (FB; Polysciences) was inserted into area MT as a crystal ( $\sim 200 \mu \mathrm{m}$ in diameter) with the aid of a blunt tungsten wire (see Fig. 2). The neocortex was first covered with a piece of sterile absorbable gelatin film (Gelfilm; Pharmacia and Upjohn) and then covered with the dura. The bone fragment removed during the craniotomy was replaced and secured with tissue adhesive (Vetbond; $3 \mathrm{M})$ before suturing. The animals were administered glucose saline subcutaneously, an analgesic (carprofen, $4 \mathrm{mg} \cdot \mathrm{kg}^{-1}$, s.c.; buprenorphine, $0.01 \mathrm{mg} \cdot \mathrm{kg}^{-1}$, i.m.), and dexamethasone $\left(0.3 \mathrm{mg} \cdot \mathrm{kg}^{-1}\right.$, i.m.) to prevent cerebral edema.

To detect whether neurons in the pulvinar nucleus and LGN pathways were visually responsive, we profiled the expression of the cFos protein by immunohistochemistry. After $16 \mathrm{~h}$ of dark adaptation (Sia and Bourne, 2008), animals at P14 and adult age that had had tracer injections $7 \mathrm{~d}$ prior were dark adapted for $16 \mathrm{~h}$ and then exposed for $45 \mathrm{~min}$ to ambient light in the laboratory with a $150 \mathrm{~W}$ lamp directly over their cage before being overdosed and transcardially perfused (see Histology and immunohistochemistry, below). To discern true cFos protein upregulation, the light stimulated animals were compared to age matched animals that were killed immediately after dark adaptation.

Histology and immunohistochemistry. Allowing $7 \mathrm{~d}$ for tracer transport, animals were subsequently overdosed with pentobarbitone sodium (100 $\mathrm{mg} \cdot \mathrm{kg}^{-1}$ ) and transcardially perfused with $0.1 \mathrm{M}$ heparinized $\mathrm{PB}, \mathrm{pH}$ 7.2 , followed by $4 \%$ paraformaldehyde in $0.1 \mathrm{M} \mathrm{PB}$. Brains were sectioned coronally on a cryostat at $40 \mu \mathrm{m}$ in 5 series. Series 3 was mounted immediately and coverslipped using Dako Fluorescent Mounting Medium. This series was used for plotting CTb and FB fluorescent labeling in the injection site (area MT), V1, LGN, and pulvinar nucleus. After comple- 
Table 1. Breakdown of animals used

\begin{tabular}{|c|c|c|c|}
\hline \multicolumn{2}{|c|}{ Immunohistochemistry } & \multicolumn{2}{|c|}{ Neuroanatomical tracing } \\
\hline Age (PD) & $n$ & Age (PD) & $n$ \\
\hline 0 & $2^{a}$ & 7 & 1 \\
\hline 3 & $1^{a}$ & 8 & 1 \\
\hline 7 & $1^{a}$ & 14 & $1^{b}$ \\
\hline 14 & $2\left(1^{a}\right)$ & 18 & 1 \\
\hline 21 & $1^{a}$ & 30 & 1 \\
\hline 28 & $1^{a}$ & 60 & 1 \\
\hline 30 & 2 & 90 & 1 \\
\hline 42 & $1^{a}$ & 180 & 1 \\
\hline 54 & 1 & 270 & 1 \\
\hline 58 & 1 & Adult & $4^{b}$ \\
\hline 67 & 1 & & \\
\hline 90 & 1 & & \\
\hline 93 & $1^{a}$ & & \\
\hline 147 & 1 & & \\
\hline 270 & 1 & & \\
\hline Adult & $4^{a}$ & & \\
\hline Total & 23 & Total & 13 \\
\hline
\end{tabular}

In total, 36 animals were used. The second and fourth columns $(n)$ indicate the number of animals analyzed at each time point.

${ }^{a}$ Data are for animals from previous studies (Bourne and Rosa, 2006; Bourne et al., 2007).

${ }^{b}$ One PD 14 and one adult animal underwent tracer injections and CFos protocols, and were not used in the FBlabeled cell count analysis.

tion of plotting the coverslips were removed, the sections allowed to air dry, and then the series was stained for Nissl substance using $0.1 \%$ cresyl violet solution. Series 5 was reacted for myelin using a modification of the Gallyas (1979) silver impregnation technique for slide-mounted sections. Both the Nissl substance and myelin stains were to assist with the demarcation of visual cortical areas and layers.

Area MT was identified by myelin-staining (adults, heavily myelinated area; see Fig. $2 C^{\prime}$ ) or by nonphosphorylated neurofilament H (NNF; monoclonal mouse anti-SMI-32; Sternberger Monoclonals; 1:2000) labeling (young brains; see Fig. 2C). Its location was transposed onto fluorescent photomicrographs of the FB injection site using reference points such as corresponding blood vessels and location within area MT established before proceeding further. To demarcate the subnuclei of the pulvinar nucleus, Series 2 was immunoreacted for calbindin-D28k (CalB; monoclonal mouse anti-calbindin-D28k; Swant; 1:10,000) following our previously described protocol (see Fig. 2B) (Warner et al., 2010). Layers of the LGN (see Fig. 2A), neocortical layers in V1 (see Fig. $5 B$ ) and area MT, the V1/V2 border, and layer 3C of V1 (see Fig. 5A) were identified using Series 3 Nissl substancestained sections. Series 4 was labeled for parvalbumin (PV; polyclonal rabbit anti-parvalbumin; Swant; 1:3000) expression in V1 and area MT during postnatal development (Bourne et al., 2007).

Cell phenotype and visual activity. To determine whether area MT input neurons were cFos (immediate-early gene protein product) positive, as well as to determine their neuronal phenotype, we performed triple labeling. For PIm, this was FB-CalB-cFos and FB-PV-cFos, and for V1, it was FB-NNF-cFos. Double labeling of FB-CalB, FB-PV, and FB-cFos was performed in the LGN. Following adequate rinses in PBS, sections were incubated for $1 \mathrm{~h}$ at room temperature in blocking solution (7\% normal goat serum in $0.3 \%$ Triton X-100 detergent and PBS). All sections to be triple labeled (PIm and V1) were incubated with a mixture of cFos (1: 15,000; Calbiochem) and CalB, PV, or NNF antibodies in blocking solution for $16 \mathrm{~h}$ at $4^{\circ} \mathrm{C}$ on a shaker. Following adequate rinsing, they were incubated with a mixture of goat anti-rabbit Alexa Fluor 594 (1:800) for Fos and goat anti-mouse Alexa Fluor 488 (1:800) for PV, CalB for PIm, or NNF for V1 sections for $1 \mathrm{~h}$ at room temperature; rinsed; mounted; and coverslipped. LGN sections were incubated with anti-PV, CalB, or cFos in blocking solution for $16 \mathrm{~h}$ at $4^{\circ} \mathrm{C}$ on a shaker, and, following adequate rinsing, were incubated in goat anti-rabbit Alexa Fluor 594 (1:800) for $1 \mathrm{~h}$ at room temperature, rinsed, mounted, and coverslipped.

For all immunohistochemical assays, negative (omission of primary antibody) and positive controls (adult tissue at the level of V1/V2) were performed routinely to ensure the consistency of labeling between immunohistochemical assays.
Data and image collection. Fluorescent-labeled sections were examined using a Zeiss Axioplan 2 epifluorescence microscope. Labeled neurons and retinal terminals were identified using $20 \times$ or $40 \times$ dry objectives, and their locations mapped with a digitizing system (MDPlot3; AccuStage). Nissl substance and myelin-stained sections of the dorsal visual thalamic nuclei and cortex were photographed under bright-field microscopy. Photomicrographs $(1300 \times 1030 \mathrm{dpi})$ were obtained with Zeiss $2.5 \times$ and $5 \times$ Plan-Neofluar objectives and acquired as digital images using a Zeiss AxioCam digital camera connected to AxioVision software (version 4.2; Zeiss). After demarcation of the PIm, LGN and V1, digitized images of sections from the areas of interest were aligned with the results from MDplot in Illustrator (Adobe Creative Suite 4) to identify the position of FB-labeled cells (see Fig. $2 B^{\prime}$ ) and retinal input, and were subsequently quantified using MDplot. Epifluorescence $z$-stacks (10- to $20-\mu \mathrm{m}$-thick stacks at an interval of $0.5 \mu \mathrm{m}$ ) were acquired, using an Axio Image.Z1 (Zeiss) microscope equipped with Plan Apochromat Oil $63 \times / 1.4$ lens, of triple- and double-labeled cells and terminals from two sections of each combination/animal. Colocalization of retinal afferents surrounding retrograde-labeled FB-positive cell bodies in the PIm were analyzed in three dimensions using an Axio Image.Z1 Apotome microscope (Zeiss). Colocalization was evaluated in single optical planes taken through the entire $z$-axis of each cell. All images were cropped and sized using Adobe Photoshop and Illustrator.

Novel quantitative analysis of inputs to area MT: area MT relay cells. The absolute number of cells labeled in the areas of interest cannot be directly compared across all ages because the size of the crystal varied between animals, and we have no information regarding the density of terminals from the area MT projection neurons in the PIm, V1, or LGN at different ages. We assume that all terminals in all layers of area MT have taken up FB because both the FB injection core and halo impacted all layers in each individual subject. We calculated the proportion of neurons projecting to area MT for each afferent region of interest (ROI). For example, for a certain age, the proportion of input from the PIm to area MT would be given by PIm/(PIm + V1 + LGN $)$. Using this ratio, we determined the contribution of each region to area MT over the developmental period. With these results, we then compared the ratios of the input to area MT before and after P90 from the PIm and V1 (V1/PIm) and the LGN (LGN/ PIm) by combining subjects up to and including P90 and after P90. Statistical comparisons were achieved using the two-tailed Mann-Whitney $U$ test, and a value of $p<0.05$ was considered significant. All data are presented as mean \pm SEM.

Analysis of cFos expression/visual activity. Following qualitative observations, the intensity of cFos immunolabeling was quantified to elucidate the difference between baseline activity and an upregulation pattern. The intensity of 60 immunopositive cell profiles throughout the PIm of examined animals was determined. The background neuropil profile was taken from 60 points throughout each PIm, and the average was calculated. The intensity profile of each PIm was then expressed as a percentage, known as the immunoreactivity (IR) index, which was adapted from Goodchild and Martin (1998) and Sia and Bourne (2008). The IR index was calculated from the following equation: IR index $=\left(1-I_{\mathrm{bg}} / I_{\text {cell }}\right) \times$ 100 , where $I_{\text {cell }}$ is the average intensity of all the cells, and $I_{\mathrm{bg}}$ is the average background intensity of the tissue in that field. The IR index increases with immunostaining intensity. The IR index in the PIm of normal lightstimulated animals was compared with corresponding regions in the age-matched, dark-adapted control to establish any statistically significant trends in Fos protein expression. This was achieved using two-tailed Mann-Whitney $U$ test, and a value of $p<0.05$ was considered significant. All data are presented as mean \pm SEM.

\section{Results}

Our study was designed with the principal aim of understanding whether dorsal visual thalamic relays that directly innervate visual cortical area MT (Fig. 1) could be responsible for the early maturation of this area. In addition, we were interested in deciphering whether these pathways adapted during the maturation of the visual cortex. Through a combination of anterograde and 


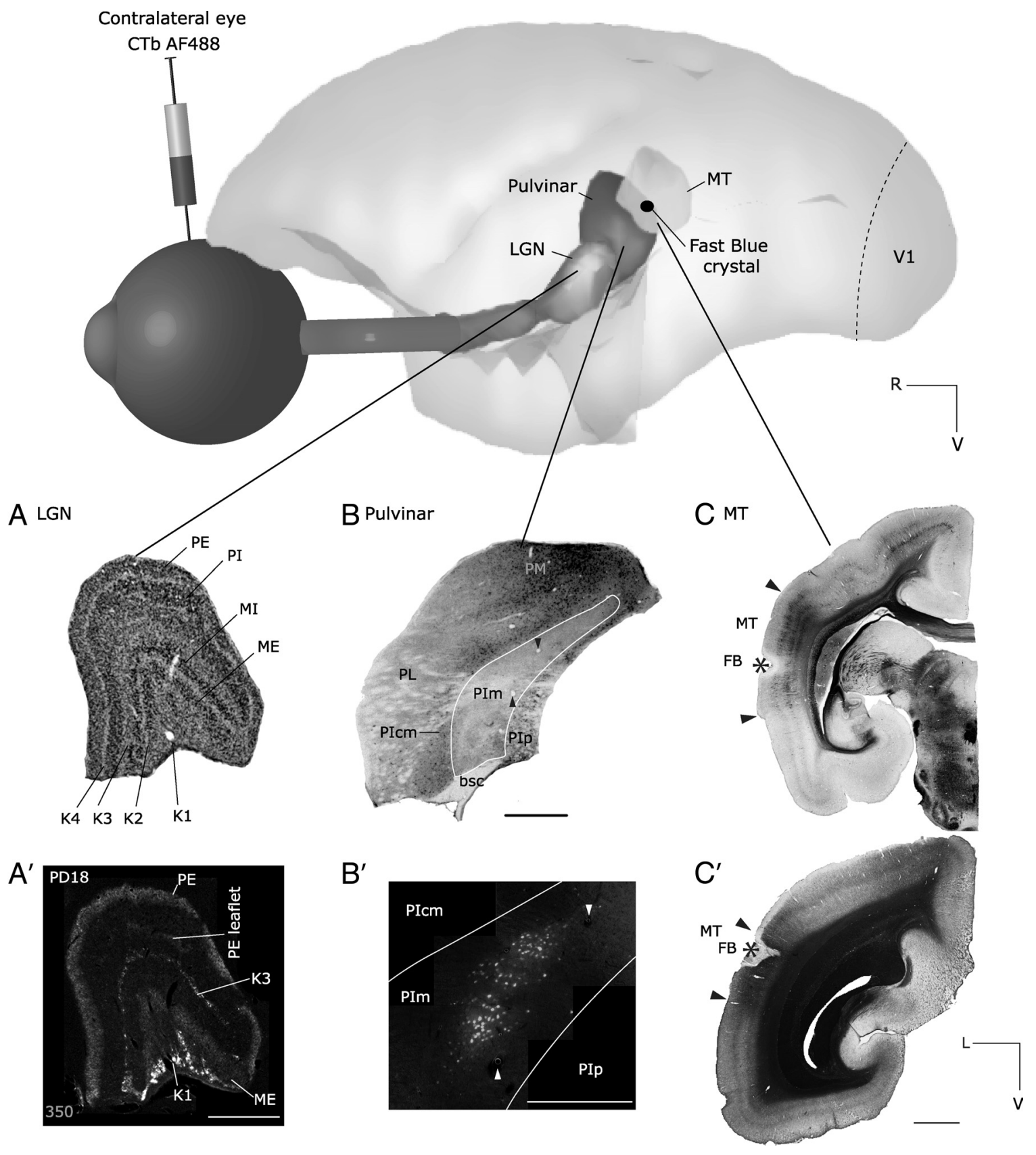

Figure 2. Protocols used for identification of retinothalamo-MT and V1-MT pathways, and demarcation of dorsal visual thalamic nuclei and visual cortical areas. To demonstrate the disynaptic retinothalamic-MT pathways via the LGN and pulvinar nucleus, an FB crystal was inserted into area MT using a tungsten rod, and CTb-AF488 was injected into the contralateral eye using a glass pipette attached to a $10 \mu \mathrm{l}$ microsyringe. $\boldsymbol{A}, \boldsymbol{A}^{\prime}$, Niss I substance-stained coronal sections of the LGN $(\boldsymbol{A})$ were used to demarcate the layers and define the location of FB-labeled cells and $(T b-l a b e l e d$ contralateral eye afferents $\left(\boldsymbol{A}^{\prime}\right)$ from adjacent sections. $\boldsymbol{B}$, Calbindin-D28k immunolabeling was performed on coronal sections to demarcate the subnuclei of the pulvinar nucleus, especially the calbindin-D28k negative PIm. $\boldsymbol{B}^{\prime}$, Adjacent sections were then examined for their expression of FB and CTb-AF488. Blood vessels ( $\boldsymbol{B}, \boldsymbol{B}^{\prime}$, arrowheads) were matched between images to ensure accurate demarcation. $C$, Nonphosphorylated neurofilament immunoreactivity was examined in young animals (younger than P60) to ensure correct location of FB injection site in area MT (P18 is shown; asterisk indicates the $\mathrm{FB}$ crystal site). $C^{\prime}$, In addition, myelin staining was used in older animals to assist with demarcation of area MT and ensure accurate placement of $\mathrm{FB}$ crystal. Posterior (PIp) and centromedial (PIcm) portions of the inferior pulvinar (PI) nucleus and lateral (PL) and medial pulvinar (PM) nuclei are shown. R, Rostral; V, ventral; L, lateral. Scale bars: $\boldsymbol{A}^{\prime}$ (for $\left.\boldsymbol{A}^{\prime}, \boldsymbol{A}\right), \boldsymbol{B}$, $1 \mathrm{~mm} ; \boldsymbol{B}^{\prime}, 500 \mu \mathrm{m} ; \boldsymbol{C}^{\prime}$ (for $\left.\boldsymbol{C}, \boldsymbol{C}^{\prime}\right), 2 \mathrm{~mm}$.

retrograde tracing (Fig. 2) in marmoset monkeys aged P7 to adult, we identified retrograde-labeled area MT relay cells coincident with contralateral eye afferents in the pulvinar nucleus and the LGN. The area MT relay cells originating in the PIm were visually driven (cFos + ) at P14, while the LGN relay cells were negative at this stage. Investigation of the dynamic contributions of V1, LGN, and PIm inputs to area MT suggests that the primary drivers are the visually sensitive PIm neurons in early postnatal life, which is overtaken by a substantially stronger input from V1 after P90. LGN neurons play little role at any stage.

\section{Maturation profile of retinal innervation of the pulvinar nucleus and LGN}

We first demarcated the layers and subnuclei of the maturing dorsal visual thalamic nuclei using a combination of histological and immunohistochemical techniques (Lyon et al., 2010; Warner 


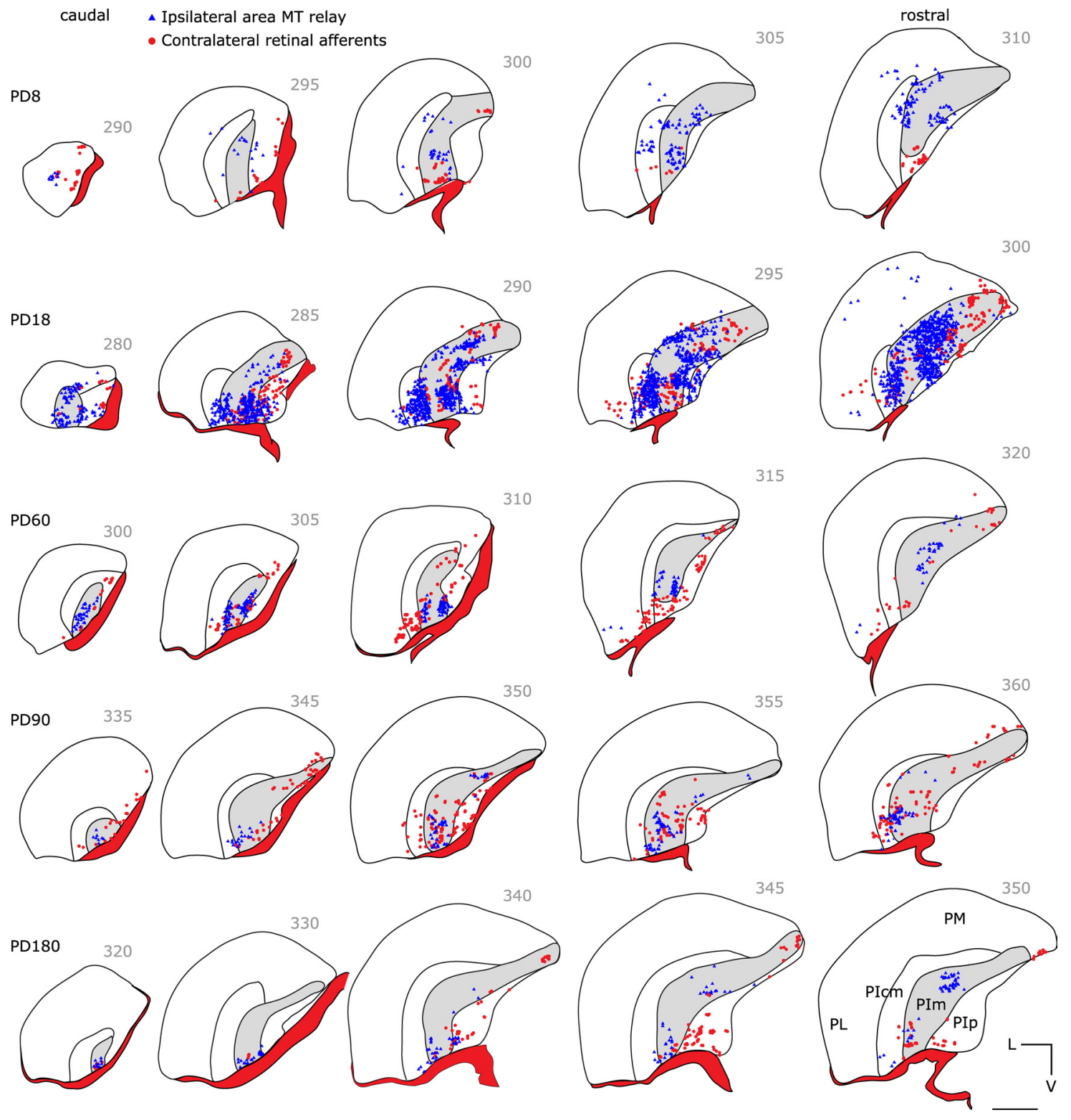

Figure 3. Retrogradely labeled neurons and anterogradely labeled retinal afferents in the PIm following area MT and contralateral eye injections at different stages of postnatal development. Digitized line drawing of the pulvinar nucleus and its subdivisions demonstrating the distribution of area MT retrogradely labeled cell bodies (blue triangles) and contralateral retinal afferents (red dots; pseudocolored). Coronal sections of the left hemisphere pulvinar nucleus at similar levels are shown, arranged caudally to rostrally (left to right) for younger to older (top to bottom row) animals studied. Retrogradely labeled area MT-projecting cells can be found in PIm at all ages studied, as well as input from the contralateral eye. Retinal fields are much easier to detect at younger ages and seem to be concentrated along a dorsomedial-to-ventrolateral axis. At older ages, contralateral retinal labeling becomes harder to find and are more commonly found in the ventral portion of PIm. Abbreviations are as shown in Figure 2. Numbers indicate section numbers counted from the caudal pole. Scale bar, $1 \mathrm{~mm}$.

et al., 2010). LGN layers are easily identified on Nissl substancestained coronal sections (Fig. $2 \mathrm{~A}$ ), while demarcation of the PIm is observed as a region lacking CalB expression (Fig. 2B) (Cusick et al., 1993). Intravitreal injection of CTb-AF488 in the right eye resulted in bilateral terminal labeling in the pulvinar nucleus, but for the purpose of this study only the contralateral retinal labeling of the left pulvinar nucleus and LGN are reported.

Labeled retinal terminals were observed at the earliest time points studied for neuroanatomical tracing experiments, P7 and P8, throughout the entire rostral-caudal extent of the PIm (Fig. 3 , P8, red dots) as dense nets of putative boutons surrounding cell bodies [see Fig. 7A, F, $G$ (P14), $F^{\prime}, G^{\prime}$ (adult)]. Swellings along a string indicative of putative boutons en passant were analogous to those described previously in the adult (Warner et al., 2010). For clarity, only putative boutons en passant and not fibers of passage were plotted. Retinal labeling was dense up to P90 (Fig. 3, red dots), but by P180 the terminal labeling frequency reduced. This pattern of reduction continued until the very sparse adult pattern was achieved (Warner et al., 2010). From P7 to adulthood, the pattern of PIm labeling was similar across the dorsalventral axis, but was more evident in the early postnatal ages (P8 and P18; Fig. 3). In addition, from P7 to adulthood there was a $27 \%$ increase in volume of PIm, whereas there was a decrease of $75 \%$ in retinal afferent density, suggesting that the observed decrease in retinal input (terminal boutons) is due to refinement of connections rather than expansion of the PIm.

Contralateral retinal labeling filled the entire LGN (Fig. $2 A^{\prime}$ ), following intravitreous injection of the CTb-AF488 tracer, so we assume that the labeling in the pulvinar nucleus represents the full extent of retinal input. The retinal input in all layers was 
restricted to specific layers and leaflets at P7 (Fig. 4, gray shading). As was demonstrated previously, input from the contralateral eye was observed in the external parvocellular (PE) and magnocellular (ME) layers of the LGN (Fig. 4, dark gray). Contralateral labeling was also detected in the koniocellular layers K1 and K3 (Fig. 4, light gray). There was also likely labeling in $\mathrm{K} 2$ and $\mathrm{K} 4$, but due to their proximity to ME and PE, these could not be unambiguously identified. For all cases, the relative density of retinal input was less in the koniocellular layers compared with the magnocellular or parvocellular layers. In addition, retinal terminals in $\mathrm{PE}$ and $\mathrm{ME}$ formed a fine, tightly woven meshwork, whereas in $\mathrm{K} 3$ and especially in $\mathrm{K} 1$, retinal afferents formed large bulbous varicosities (Figs. 2A'; 7B, white arrowhead).

\section{Area MT is recipient of direct input from the PIm, LGN, and V1}

Previous studies have demonstrated the presence of two monosynaptic pathways from the pulvinar nucleus and LGN to area MT in adult nonhuman primates (Lin and Kaas, 1980; Cowey et al., 1994; Adams et al., 2000; O'Brien et al., 2001; Warner et al., 2010), but none have examined when they are present and whether they change during development. Therefore, injection of the retrograde tracer FB into area MT (Fig. 2) was performed to determine whether changes in the PIm and LGN input to area MT is observed throughout early life and into adulthood. Examination of the injection site was made to ensure that the injection had not impinged upon the white matter, but at least the halo extended to layer 6 of area MT in each of the cases (Fig. 2C, $C^{\prime}$ ). CalBimmunostained sections identified the PIm (Fig. $2 B$ ), and Nissl substance staining defined layers of the LGN and V1 (Figs. 2A, 5B).

At P7 and P8, the majority of relay cells projecting to area MT were restricted to the PIm (Fig. 3, blue dots), with occasional cells observed in adjacent pulvinar subnuclei as we observed previously in the adult (Warner et al., 2010). Retrograde cellular labeling was also observed in the LGN (Fig. 4, blue triangles) for all ages studied. FB-positive LGN neurons were found primarily in the K layers, but LGN labeling was only a fraction compared to PIm labeling (Fig. 3). For instance, in all cases examined, LGN labeling was restricted to one to two sections, whereas labeling was observed throughout the majority of the rostral-caudal axis of PIm. At no age were any FB-labeled cell bodies found in the contralateral pulvinar nucleus or LGN.

In addition, $\mathrm{FB}$ injections in area $\mathrm{MT}$ resulted in cell body labeling in layer $3 \mathrm{C}$ (layer $4 \mathrm{~B}$ in macaque) of ipsilateral V1 (Fig. 5), restricted to the retinotopic location of the injection site. Scale bar, $1 \mathrm{~mm}$.
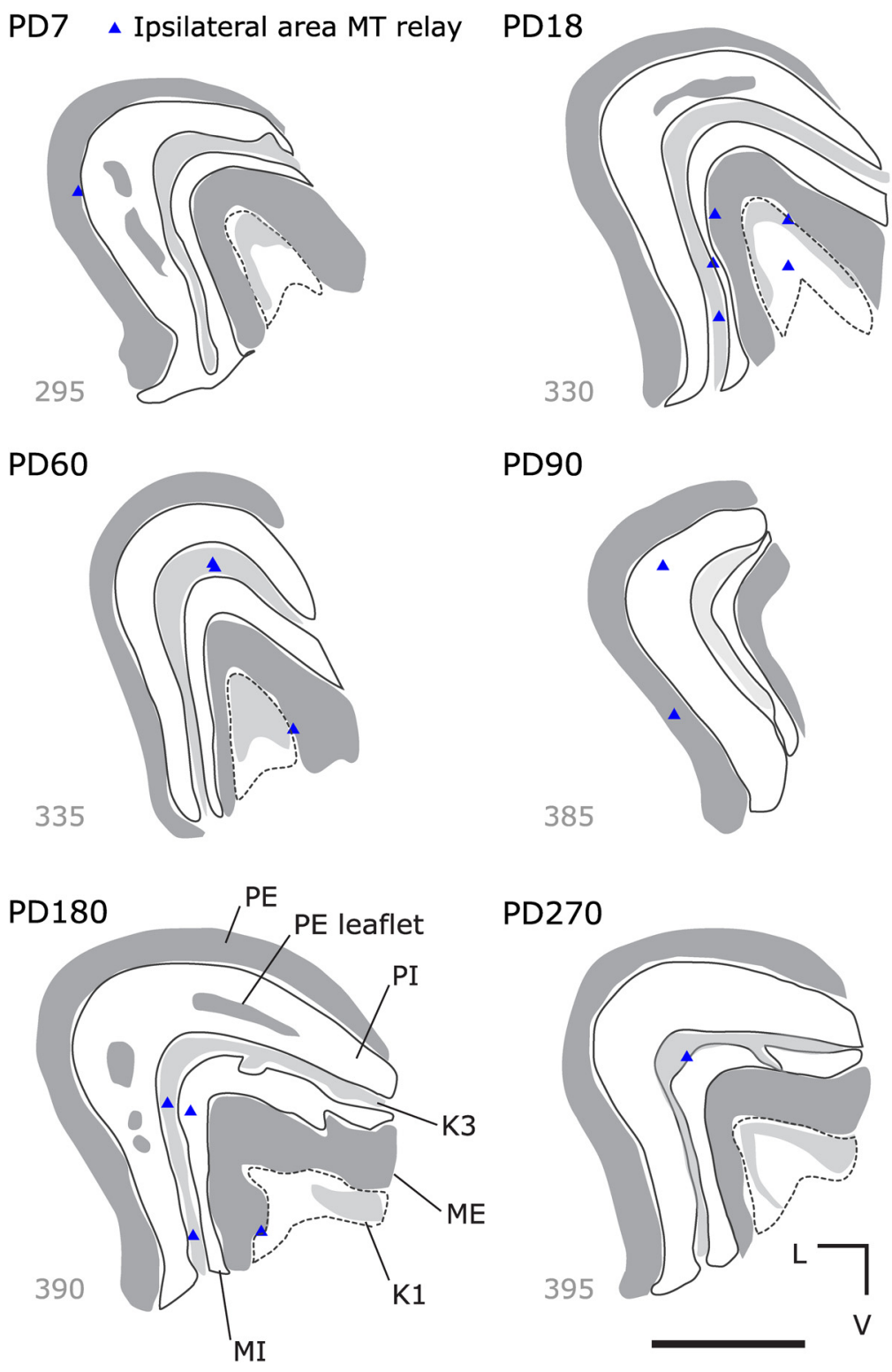

Figure 4. Retrogradely labeled neurons and contralateral retinal afferent terminals in the LGN following area MT and contralateral eye injections at different stages of postnatal development. Digitized line drawings of the left-hemisphere LGN in the coronal plane are shown, overlaid with FB-labeled MT relay cells (blue triangles) across all ages studied. Gray areas indicate regions K1 and K3 of the LGN. Numbers indicate section numbers counted from the caudal pole. Abbreviations are as shown in Figure 2.

\section{The PIm pulvinar subnucleus relay to area MT, unlike the} LGN relay, is dynamically modulated from the early postnatal period through to adulthood

One persistent difficulty in quantitative assessment of retrograde neural tracing is the inability to control for uptake of the tracer, despite all efforts to keep FB crystals at a similar size and insert them at a similar depth, yielding a variation in the number of labeled cells projecting to the injected area. This variability makes it impossible to compare between different subjects and thus demonstrate a developmental profile for specific pathways. The absolute numbers vary significantly between subjects, even those of a similar age (Table 2). Therefore, to account for these differences, we compared the contribution of each ROI as a percentage of the total input to area MT from the PIm, LGN, and V1 (see Materials and Methods). When the resultant data were graphed 

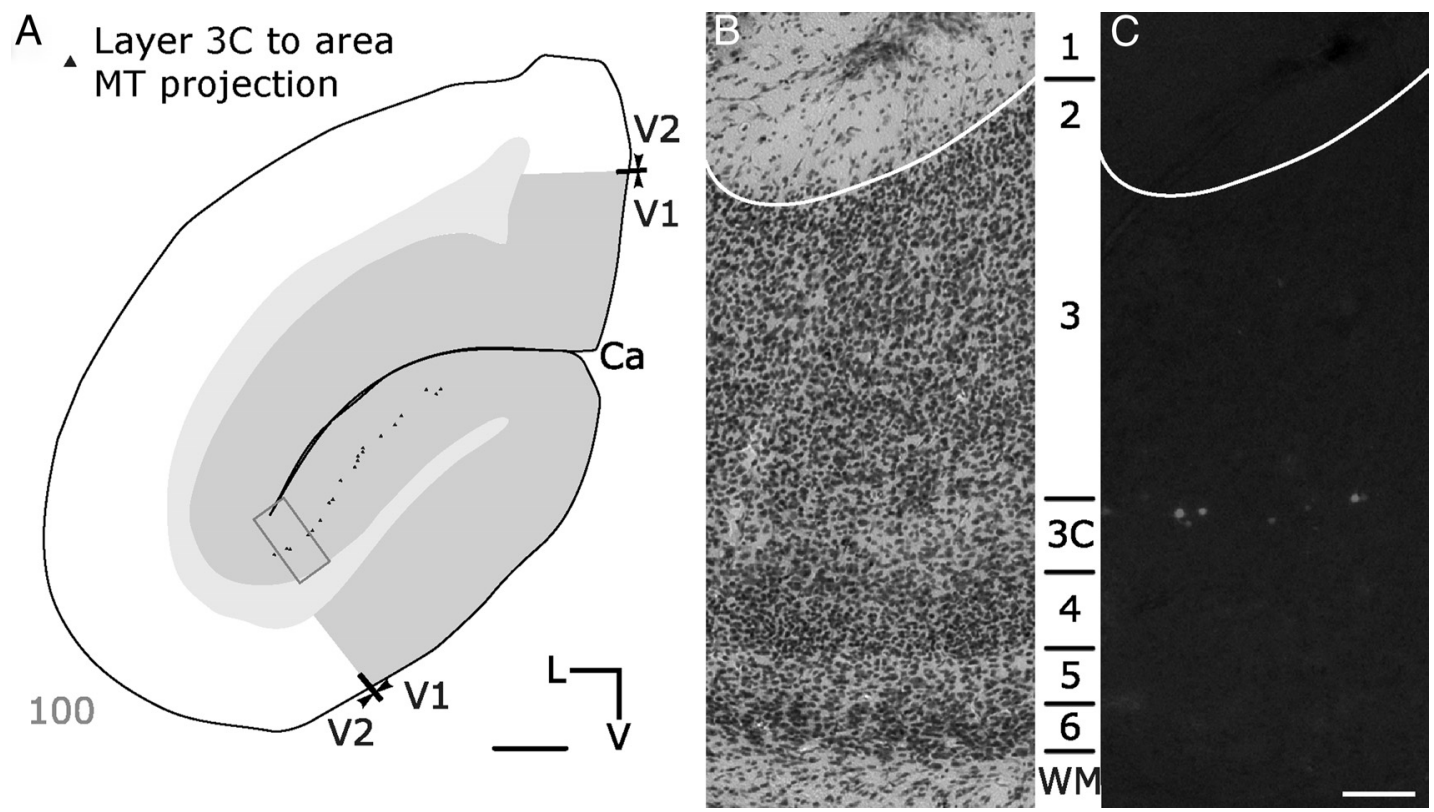

Figure 5. Fast blue-labeled cells projecting to area MT were observed in layer 3 C of a discrete retinotopic region of V1. A, A digitized line drawing of a V1 (shaded area) coronal section from a P18 animal demonstrating the location of FB-labeled area MT-projecting cells (black triangles). $\boldsymbol{B}$, To confirm the laminar distribution, adjacent Nissl substance stained-sections were used (outlined region in $\boldsymbol{A}$ ). $\boldsymbol{C}$, This enabled us to verify that the FB-labeled area MT-projecting cells were specifically localized to layer $3 C$. The bottom left number in $\boldsymbol{A}$ indicates the section number counted from the caudal pole. Ca, Calcarine sulcus; WM, white matter. Scale bars: $A, 1 \mathrm{~mm} ; \boldsymbol{C}($ for $B, C), 100 \mu \mathrm{m}$.

\section{Table 2. Absolute counts of fast blue-labeled cells in the V1 and visual thalamus}

\begin{tabular}{lrrr}
\hline & \multicolumn{3}{c}{ Fast Blue-labeled cell counts } \\
\cline { 2 - 4 } Age (PD) & PIm & \multicolumn{1}{c}{ V1 } & LGN \\
\hline 7 & 44 & 6 & 1 \\
8 & 124 & 45 & 1 \\
18 & 1823 & 411 & 14 \\
30 & 580 & 607 & 17 \\
60 & 265 & 285 & 3 \\
90 & 74 & 85 & 3 \\
180 & 430 & 1115 & 4 \\
270 & 5 & 16 & 1 \\
Adult & 209 & 2588 & 13 \\
Adult & 500 & 5481 & 10 \\
Adult & 423 & 2095 & 28 \\
\hline
\end{tabular}

(Fig. 6A), a striking feature was that between P7 and P30, the PIm (red circles) contributed more input to area MT than either V1 (blue squares) or LGN (green triangles). Between P30 and P90, the PIm and V1 had similar input to area MT, and after P90, the proportion of input from V1 increased and became the dominant input. The contribution from the LGN remained minimal and unchanged throughout development (Fig. 6A). To determine whether there was any significance in the proportion of input between the regions of interest during development and maturation of the visual cortex, we divided the cohort of subjects into two groups; one group comprised animals of age P7-P90 $(n=6)$, and the other group animals older than P90 $(n=5)$. To establish whether a significant difference existed in the ratio of input to area MT from the PIm, LGN, or V1, animals were grouped into those aged P7-P90 and those over P90, and a two-tailed MannWhitney $U$ test was performed. A significant difference was observed between the PIm and V1 of the two groups (Fig. $6 B$; $p=$ 0.0079), but not between the PIm and the LGN (Fig. 6C). This evidence from the FB tracer analysis suggests an earlier dominance of PIm and a later dominance of V1 input to area MT.
Soon after birth, area MT-projecting neurons in PIm express parvalbumin, colocalize with retinal afferents, and demonstrate visual activity

Previously we demonstrated the colocalization of retinal synapses with the cell bodies of area MT relay cells in the adult PIm (Warner et al., 2010). By P14, we observed the similar close proximity of contralateral retinal terminals in the vicinity of area MTprojecting cells in the PIm (Fig. 7A), identical to that observed in the adult (Fig. $7 F^{\prime}, G^{\prime}$ ). The majority of the afferent terminals at P14 juxtaposed the cell bodies of the area MT relay cells (Fig. $7 A, F, G$ ), and while it was not possible to identify the dendrites of the FB positive cells, few terminal fields were observed distal to the cell body that might suggest colocalization with their dendrites. In the LGN, there were very few terminal fields in proximity to the FB-labeled cells (Fig. $7 B$, white arrow), but many fibers of passage.

Examination of the relay cell activity through expression of the immediate-early gene protein product cFos enabled us to test whether these PIm and LGN neurons were visually driven at both $\mathrm{P} 14$ and in the adult. The expression of cFos in FB-labeled relay cells coincident with labeled retinal input [Fig. $7 F, G(\mathrm{P} 14), F^{\prime}, G^{\prime}$ (adult)] indicates that this input was capable of driving the cell. P14 was the earliest age studied for cFos expression due to the nature of the protocol. To qualify our results, we compared the cFos expression of visually stimulated (Fig. 7C) with non-visually stimulated (Fig. 7D) animals, and subsequently performed an IR index calculation. With this, we established a baseline IR index of $20 \%$, although all of our calculations of the area MT relay cells of visually stimulated animals revealed that cFos levels were $>50 \%$ and were statistically different from the controls (Fig. 7E).

At P14 and in the adult, all visually responsive FB-labeled area MT relay cells in the PIm colabeled with PV but not CalB or NNF (Fig. 8B, $B^{\prime}, C, C^{\prime}$ ). Initial examination of immunofluorescence revealed intensely $\mathrm{PV}$-immunolabeled cells that were not $\mathrm{FB}$ labeled (Fig. $8 A, \mathrm{P} 14 ; A^{\prime}$, adult, black arrows), and lightly PVimmunostained cell bodies that were FB labeled (Fig. 7A, P14; $A^{\prime}$, 
adult, unfilled arrows). FB-labeled cells in the LGN expressed CalB (Fig. $8 D, \mathrm{P} 14 ; D^{\prime}$, adult), which lacked cFos expression at P14 (Fig. $8 E$ ) but became visually activated by adulthood (Fig. $8 E^{\prime}$ ). At P14 and in adult, layer 3C of V1 neurons, which project directly to area MT, expressed NNF, and cFos expression was observed at both time points but more prominent in the adult (Fig. $8 F, \mathrm{P} 14 ; F^{\prime}$, adult).

Because of the low number of relay cells projecting to area MT from the LGN and the observed lack of change during postnatal development, we did not continue with the analysis of the retinogeniculo-MT pathway beyond this point.

\section{Cellular/laminar maturation of V1 and area MT}

To determine the temporal events associated with the dynamic connectivity between the PIm and MT and V1 and MT, and their influence on the postnatal maturation of area MT, we examined the expression of the calcium-binding protein PV in both area MT and V1 from P0 to adulthood.

Previously, the developmental immunoreactivity pattern of PV in $\mathrm{V} 1$ of humans and nonhuman primates was linked with the onset of activity (Hendrickson et al., 1991; Letinic and Kostovic, 1998; Bourne et al., 2007). PV expression in cell bodies is considered to be an indicator of the onset of visual responsiveness, whereas PV expression in neuropil is correlated with the completion of thalamocortical connections (Hendrickson et al., 1991). We thus used PV expression to examine the maturation profile of neurons in area MT and V1, with the hope of gaining insight into the relative prominence of the pulvinar nucleus and V1 afferents to area MT based on known laminar differences in the connection pattern. We specifically examined layer 3C of $\mathrm{V} 1$ as well as the input layers 3 and 4 of area MT with which both PIm and V1 terminate. The pulvinorecipient layer in area MT is primarily in deep layer 3 (Spatz, 1975; Trojanowski and Jacobson, 1976; Rockland 1989, 1995; Anderson et al., 1998; Rockland et al., 1999).

No PV-immunopositive cells were detected in either layer 3C of $\mathrm{V} 1$ or layer 4 of MT at P0 or P7, but were present by P14, suggesting that the direct V1-MT projection may not be fully mature at this stage (Fig. 9). In contrast, the pulvinorecipient deep layer 3 of area MT contained PV + cells as early as P3. Together these findings suggest that the visual responsiveness of area MT between P0 and P3 may come not from V1, but instead the PIm, and that not until between P7 and P14 does V1 start exerting an influence on area MT (Fig. 10).

\section{Discussion}

Previously it was hypothesized that the visual cortex develops in a hierarchical fashion with higher-order areas developing later, driven by feedforward projections from previously developed lower-order cortical areas (Guillery, 2005). Hence, all extrastriate cortex development would be dependent on the initial maturation of V1; however, area MT, an extrastriate area, develops early and in parallel with V1 (Condé et al., 1996; Bourne and Rosa, 2006). But what is driving this early maturation? Here we demonstrate a disynaptic retinopulvinar input through the PIm to area MT that is more dominant soon after birth than either the direct projection from V1 or LGN. Thereafter, the proportion of V1 input to area MT increases to equal that of the PIm then eventually surpasses it in later stages of development to reach adult levels and become the dominant input. Meanwhile, the proportion of input from LGN throughout postnatal development is small compared to that from either the PIm or V1. This suggests that the early maturation of area MT could be due to the presence of a disynaptic retinopulvinar input, bypassing $\mathrm{V} 1$, and not necessarily the consequence of either the direct projection from V1 or LGN (Fig. 10).

Area MT has a crucial role in motion processing in the adult primate (Allman and Kaas, 1971; Zeki, 1974, Born and Bradley, 2005). Behavioral studies have demonstrated the capacity for both macaques and marmosets to detect motion within the first month after birth (Kiorpes and Movshon, 2004; Izumi et al., 2011), and humans have the ability to discriminate direction of motion relatively early in visual development (Banton et al., 2001). Previous electrophysiological recordings from 

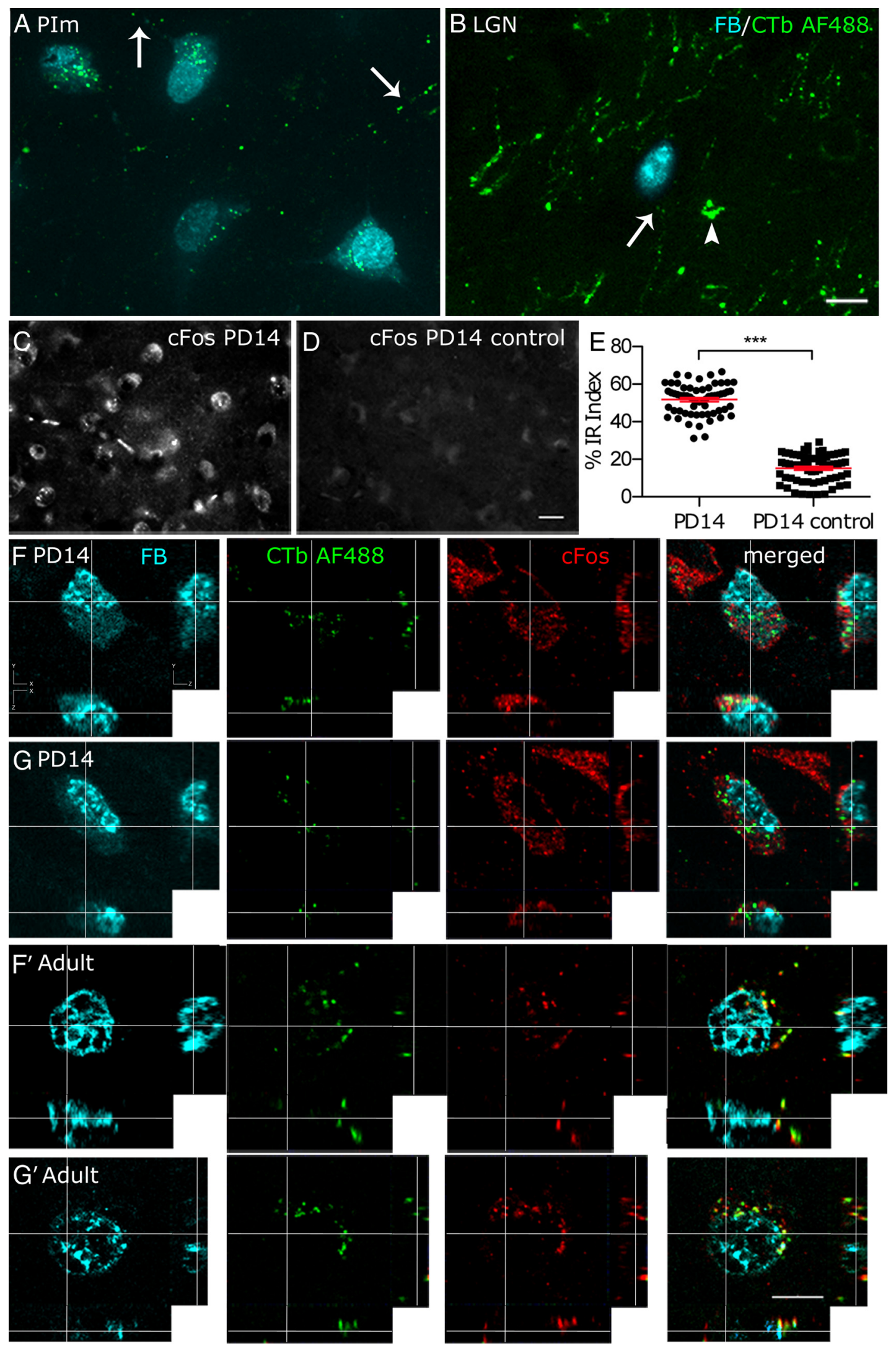

Figure 7. MT relay cells in the PIm receive contralateral retinal input and are visually driven early in postnatal life. $A, B$, At all ages studied, FB-labeled (cyan) cells in the PIm are surrounded by many contralateral retinal terminals ( $\boldsymbol{A}$, green dots surrounding cell body) and boutons en passant (white arrows), whereas for area MT-projecting cells in the LGN, only a few dots are visible surrounding the cell $(\boldsymbol{B})$, despite the abundance of labeled retinal afferent input (P14 case is used as an example). $\boldsymbol{C}-\boldsymbol{E}$, Cells in the PIm were visually active, and were determined from their cFos expression $(\boldsymbol{C})$ when statistically compared to non-visually stimulated controls $\left(\boldsymbol{D}, \boldsymbol{E}\right.$, two-tailed Mann-Whitney test, $\left.{ }^{* * *} p<0.0001\right) . \mathbf{F}-\boldsymbol{G}^{\prime}$, Apotome micrograph $z$-stacks of $F B$-labeled cells (cyan) in the PIm in the vicinity of contralaterally labeled retinal afferents (CTb-AF488, green) were also found to be visually driven, as indicated by the expression of cFos (red) as early as P14 ( $\boldsymbol{F}, \boldsymbol{G})$ to adulthood $\left(\boldsymbol{F}^{\prime}, \boldsymbol{G}^{\prime}\right)$. Abbreviations are as shown in Figure 2. Scale bars: $\boldsymbol{B}$ (for $\left.\boldsymbol{A}, \boldsymbol{B}\right), 10 \mu \mathrm{m} ; \boldsymbol{D}$ (for $\left.\boldsymbol{C}, \boldsymbol{D}\right), 20 \mu \mathrm{m} ; \boldsymbol{G}^{\prime}$ (for $\boldsymbol{F}-\boldsymbol{G}^{\prime}$ ), $10 \mu \mathrm{m}$. 

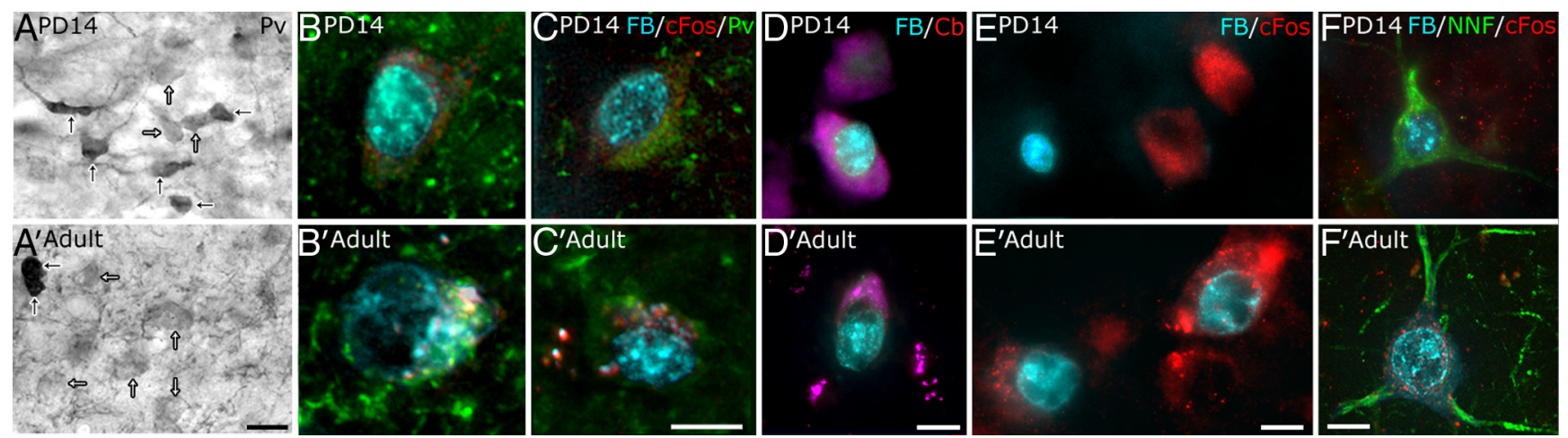

Figure 8. Area MT-projecting cells originating in the PIm, LGN, and V1 have different cell phenotypes and are not all visually driven in early life. $A, A^{\prime}$, Two populations of PV cells in the PIm were identified; light (white arrows) and dark (black arrows) cell bodies were present in both P14 (A) and in adults $\left(\boldsymbol{A}^{\prime}\right)$. $\boldsymbol{B}-\boldsymbol{E}^{\prime}$, Examples of two FB-labeled (cyan) cells proximal to contralateral retinal afferents (verified before immunofluorescence staining) were identified as light PV (green) cells expressing cFos (red) at P14 (B, C) and in adult $\left(\boldsymbol{B}^{\prime}, \boldsymbol{C}^{\prime}\right)$, whereas FB-labeled area MT relay cells located in the K layers of the LGN express calbindin-D28k (magenta; $\left.\boldsymbol{D}, \boldsymbol{D}^{\prime}\right)$ and are only visually driven in the adult $\left(\boldsymbol{E}^{\prime}\right)$ but not at P14 $(\boldsymbol{E}) . \boldsymbol{F}, \boldsymbol{F}^{\prime}, F B$-labeled area MT neurons in layer 3 (of V1 express NNF (green) at P14 (F) and in the adult $\left(\boldsymbol{F}^{\prime}\right)$ and are visually driven at both stages (cFos, red), although expression of cFos is greater in the adult. Scale bars: $\boldsymbol{A}^{\prime}, 20 \mu \mathrm{m} ; \boldsymbol{C}^{\prime}$ (for $\left.\boldsymbol{B}-\boldsymbol{C}^{\prime}\right), \boldsymbol{D}^{\prime}, \boldsymbol{E}^{\prime}, \boldsymbol{F}^{\prime}, 10 \mu \mathrm{m}$.

newborn macaque area MT demonstrate that neurons are fully direction selective (Movshon et al., 2004). However, while there are no neurophysiological data from marmoset area MT in early life, based on the caecal period of visual pathway development, a common "timetable" applied to all eutherian mammals (Robinson and Dreher, 1990), the marmoset is born with a less mature visual system than the macaque or human primate. With the knowledge that area MT is an early maturing visual cortical area, and associated function is present early in life, our data suggest that the early maturation of area MT may be subserved by the presence of the dominant disynaptic retinal input via the PIm to area MT in early life. After $\mathrm{P} 90, \mathrm{~V} 1$ input comes to dominate area MT, and the PIm retinothalamic pathway seems to regress. Because motion sensitivity gradually improves until 3 years of age in macaques (Kiorpes and Movshon, 2004), this may be due to the maturation of the direct V1-MT pathway and the indirect connections via the other extrastriate areas (Felleman and van Essen, 1991).

In the adult marmoset monkey and other nonhuman primates, area MTprojecting relay neurons have been observed in the koniocellular layers of the LGN and in retinotopic placement (Sincich et al., 2004). Because very few relay cells are observed in the LGN during early postnatal maturation, and at these ages LGN-MT relay cells are cFos negative, suggesting that they are not visually active, it is unlikely that the koniocellular LGN is contributing to the early development of area MT.

The direct input from V1 to area MT (layer 3C in marmoset, which corresponds to layer $4 \mathrm{~B}$ in macaque) is the major input to area MT in the adult (Shipp and Zeki, 1989), but may not be the influencing input in the early postnatal period. Based on NNF labeling in the newborn marmoset, which is an indicator of pyramidal cell maturation, existing projections from V1 to area MT at birth are immature (Bourne et al., 2005). In addition, PV labeling, a marker for onset of neuronal activity (Hendrickson et al., 1991), is not present until between P7P14 in layer 3C of V1 and layer 4 of MT (the V1 recipient layer) (Rockland 1989, 1995; Anderson et al., 1998). It is not until P90, the start of the "critical period" in the marmoset (Missler 


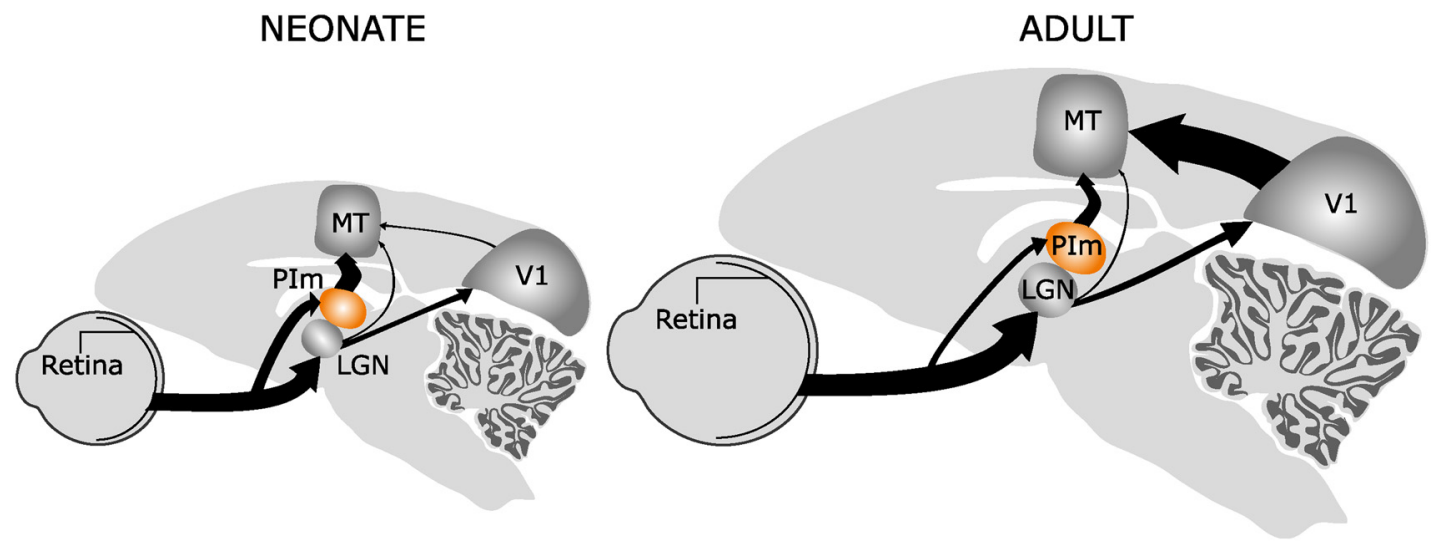

Figure 10. Summary diagrams of the retinothalamic and V1 inputs to visual cortical area MT in early life and adulthood, demonstrating relative changes in the abundance of pathways. In the neonate, the primary input to area MT is via the PIm, which is the recipient of a strong projection from the retina. However, throughout postnatal development, the direct input from the V1 to area MT strengthens, and retinopulvino-MT input diminishes to a minimal pathway by adulthood. However, the primary visual thalamic nucleus, the LGN, which also provides a direct input to area MT, does not appear to be modulated throughout this period, and the level of input remains the same as that observed soon after birth.

et al., 1993), that pyramidal cells in layer 3C of V1 have an adult morphology (Bourne et al., 2005). All of these findings strongly support a postnatal delay in the influence of input from V1 on the early development of area MT.

Further evidence for the PIm driving the early maturation of area MT comes from analysis of PV labeling in cortical layers, which is a known indicator of onset of driven activity in V1 (Hendrickson et al., 1991). Cells in deep layer 3 of area MT, the primary input layer from the PIm (Spatz, 1975; Trojanowski and Jacobson, 1976; Rockland et al., 1999), have a mature labeling shortly after birth. This supports the idea that the input from the PIm is driving the early maturation of area MT. In addition, from the earliest age studied, the PIm relay cells were cFos +/visually driven. Given the observation that in marmosets and macaques there was a capacity to detect motion soon after birth (Kiorpes and Movshon, 2004; Izumi et al., 2011), we have identified PIm input as likely driving this perceptual capability in early life.

\section{Visual cortical maturation in the primate may rely on transthalamic corticocortical connections involving the pulvinar nucleus}

Little is known about the specific function of the largest nucleus of the dorsal thalamus, the pulvinar nucleus, and its subnuclei, let alone their role in visual cortical development and maturation. Early work suggested that visual activation of neurons in the pulvinar nucleus were dependent on input from the neocortex (Bender, 1983). It is now becoming accepted that the dorsal visual thalamus, particularly the pulvinar nucleus, is not a passive relay station, but is intricately involved in the processing and modifying of cortical information (Sherman and Guillery, 2011; Purushothaman et al., 2012). The same, therefore, may be said for its involvement in visual cortical maturation. The hierarchical model of cortical maturation implies that higher-order cortical areas rely solely on their inputs from lower-order cortical fields (e.g., V1 to V4). This has lead to the assumption that for a cortical area to mature it only needs corticocortical connections, neglecting the potential role of the substantial transthalamic corticocortical connections present. We suggest that both corticocortical interactions and thalamocortical inputs are required for development of sensory cortex (Guillery, 2005). Few studies have examined the anatomical connection between the cortical and subcortical areas during development, and these are focused on the macaque (Barone et al., 1995; Batardière et al., 2002; Baldwin et al., 2012). Connections were observed from both V1 and V2 to area MT at 2 weeks, and the lateral pulvinar to $\mathrm{V} 1$ and $\mathrm{V} 2$ at 4 weeks of age in macaque monkey (Baldwin et al., 2012). It is apparent from these anatomical studies that the subcortical and cortical patterns of connections are adult-like close to birth and subsequently undergo experience-dependent refinement. Tracer studies in adult marmoset monkey demonstrated a predominance of connections between the inferior pulvinar and the dorsal stream complex, whereas the lateral pulvinar is highly connected with the ventral stream complex (Kaas and Lyon, 2007). From these studies and our own results, one could suggest that the pulvinar nucleus input to the visual cortex is present at birth, forming transthalamic loops between cortical fields that become modified during cortical maturation. What is unique with the PIm and surrounding subdivisions is that they are in a position to receive sensory/ external input at a young age, whereas the lateral pulvinar does not receive direct input from a sensory organ. This suggests the PIm is in a position to promote/support early (visual) development of the dorsal stream through direct and transthalamic corticocortical connections. The previous finding of a disynaptic superior colliculus-MT pathway via the PIm in the adult macaque (Berman and Wurtz, 2008, 2010; Lyon et al., 2010), which has a specific role in saccadic suppression and may be present at birth, could be providing a different input to area MT. This additional input further highlights the complexity of signal relays though the pulvinar nucleus and individual subnuclei, and suggests that the PIm of the pulvinar nucleus provides the opportunity to influence the initial maturation of area MT.

The ability for primates to perceive certain aspects of motion in early life appears important for survival, but much more specific aspects of motion processing will develop later in postnatal life. Therefore, the retinopulvino-MT projection in early life may allow a level of circumnavigation of decision processing about whether or not to respond to visual stimuli while more sophisticated processing is still developing. Teleologically, it seems that one reason for the early maturation of the MT-projecting pathway, besides just a step in the maturation of the extrastriate cortex, may be related to the need to understand the visual consequences of actions: reafference, spatial orientation, reaching, etc. This process might be criti- 
cal shortly after birth and may shape the dorsal stream pathway early on. Progress in these endeavors promises not only to elucidate the complexities of the pulvinar nucleus, but also to inform the understanding of how subcortical and cortical mechanisms interact to produce visual perception/development of the neocortex.

\section{References}

Adams MM, Hof PR, Gattass R, Webster MJ, Ungerleider LG (2000) Visual cortical projections and chemoarchitecture of macaque monkey pulvinar. J Comp Neurol 419:377-393. CrossRef Medline

Allman JM, Kaas JH (1971) Representation of the visual field in striate and adjoining cortex of the owl monkey (Aotus trivirgatus). Brain Res 35:89-106. CrossRef Medline

Anderson JC, Binzegger T, Martin KA, Rockland KS (1998) The connection from cortical area V1 to V5: a light and electron microscopic study. J Neurosci 18:10525-10540. Medline

Baldwin MK, Kaskan PM, Zhang B, Chino YM, Kaas JH (2012) Cortical and subcortical connections of V1 and V2 in early postnatal macaque monkeys. J Comp Neurol 520:544-569. CrossRef Medline

Banton T, Dobkins K, Bertenthal BI (2001) Infant direction discrimination thresholds. Vision Res 41:1049-1056. CrossRef Medline

Barone P, Dehay C, Berland M, Bullier J, Kennedy H (1995) Developmental remodeling of primate visual cortical pathways. Cereb Cortex 5:22-38. CrossRef Medline

Batardière A, Barone P, Knoblauch K, Giroud P, Berland M, Dumas AM, Kennedy H (2002) Early specification of the hierarchical organization of visual cortical areas in the macaque monkey. Cereb Cortex 12:453-465. CrossRef Medline

Bender DB (1983) Visual activation of neurons in the primate pulvinar depends on cortex but not colliculus. Brain Res 279:258-261. CrossRef Medline

Berman RA, Wurtz RH (2008) Exploring the pulvinar path to visual cortex. Prog Brain Res 171:467-473. CrossRef Medline

Berman RA, Wurtz RH (2010) Functional identification of a pulvinar path from superior colliculus to cortical area MT. J Neurosci 30:6342-6354. CrossRef Medline

Born RT, Bradley DC (2005) Structure and function of visual area MT. Annu Rev Neurosci 28:157-189. CrossRef Medline

Bourne JA (2010) Unravelling the development of the visual cortex: implications for plasticity and repair. J Anat 217:449-468. CrossRef Medline

Bourne JA, Rosa MG (2006) Hierarchical development of the primate visual cortex, as revealed by neurofilament immunoreactivity: early maturation of the middle temporal area (MT). Cereb Cortex 16:405-414. Medline

Bourne JA, Warner CE, Rosa MG (2005) Topographic and laminar maturation of striate cortex in early postnatal marmoset monkeys, as revealed by neurofilament immunohistochemistry. Cereb Cortex 15: 740-748. CrossRef Medline

Bourne JA, Warner CE, Upton DJ, Rosa MG (2007) Chemoarchitecture of the middle temporal visual area in the marmoset monkey (Callithrix jacchus): laminar distribution of calcium-binding proteins (calbindin, parvalbumin) and nonphosphorylated neurofilament. J Comp Neurol 500: 832-849. CrossRef Medline

Condé F, Lund JS, Lewis DA (1996) The hierarchical development of monkey visual cortical regions as revealed by the maturation of parvalbuminimmunoreactive neurons. Brain Res Dev Brain Res 96:261-276. CrossRef Medline

Cowey A, Stoerig P, Bannister M (1994) Retinal ganglion cells labelled from the pulvinar nucleus in macaque monkeys. Neuroscience 61: 691-705. CrossRef Medline

Cusick CG, Scripter JL, Darensbourg JG, Weber JT (1993) Chemoarchitectonic subdivisions of the visual pulvinar in monkeys and their connectional relations with the middle temporal and rostral dorsolateral visual areas, MT and DLr. J Comp Neurol 336:1-30. CrossRef Medline

Felleman DJ, van Essen DC (1991) Distributed hierarchical processing in the primate cerebral cortex. Cereb Cortex 1:1-47. CrossRef Medline

Gallyas F (1979) Silver staining of myelin by means of physical development. Neurol Res 1:203-209. Medline

Gogtay N, Giedd JN, Lusk L, Hayashi KM, Greenstein D, Vaituzis AC, Nugent TF 3rd, Herman DH, Clasen LS, Toga AW, Rapoport JL, Thompson PM (2004) Dynamic mapping of human cortical devel- opment during childhood through early adulthood. Proc Natl Acad Sci U S A 101:8174-8179. CrossRef Medline

Goodale MA, Milner AD (1992) Separate visual pathways for perception and action. Trends Neurosci 15:20-25. CrossRef Medline

Goodchild AK, Martin PR (1998) The distribution of calcium-binding proteins in the lateral geniculate nucleus and visual cortex of a New World monkey, the marmoset, Callithrix jacchus. Vis Neurosci 15:625-642. Medline

Guillery RW (2005) Is postnatal neocortical maturation hierarchical? Trends Neurosci 28:512-517. CrossRef Medline

Hendrickson AE, Van Brederode JF, Mulligan KA, Celio MR (1991) Development of the calcium-binding proteins parvalbumin and calbindin in monkey striate cortex. J Comp Neurol 307:626-646. CrossRef Medline

Izumi A, Tsuchida J, Yamaguchi C (2011) Effects of rearing conditions on early visual development in common marmosets. Dev Psychobiol 54: 700-705. CrossRef Medline

Kaas JH, Lyon DC (2007) Pulvinar contributions to the dorsal and ventral streams of visual processing in primates. Brain Res Rev 55:285-296. CrossRef Medline

Kiorpes L, Movshon JA (2004) Development of sensitivity to visual motion in macaque monkeys. Vis Neurosci 21:851-859. Medline

Kiorpes L, Price T, Hall-Haro C, Anthony Movshon J (2012) Development of sensitivity to global form and motion in macaque monkeys (Macaca nemestrina). Vis Res 63:34-42. CrossRef Medline

Krubitzer LA, Kaas JH (1990) Cortical connections of MT in four species of primates: areal, modular, and retinotopic patterns. Vis Neurosci 5:165204. CrossRef Medline

Labar DR, Berman NE, Murphy EH (1981) Short- and long-term effects of neonatal and adult visual cortex lesions on the retinal projection to the pulvinar in cats. J Comp Neurol 197:639-659. CrossRef Medline

Letinic K, Kostovic I (1998) Postnatal development of calcium-binding proteins calbindin and parvalbumin in human visual cortex. Cereb Cortex 8:660-669. CrossRef Medline

Lin CS, Kaas JH (1980) Projections from the medial nucleus of the inferior pulvinar complex to the middle temporal area of the visual cortex. Neuroscience 5:2219-2228. CrossRef Medline

Lyon DC, Nassi JJ, Callaway EM (2010) A disynaptic relay from superior colliculus to dorsal stream visual cortex in macaque monkey. Neuron 65:270-279. CrossRef Medline

Maunsell JH, van Essen DC (1983) The connections of the middle temporal visual area (MT) and their relationship to a cortical hierarchy in the macaque monkey. J Neurosci 3:2563-2586. Medline

Milner AD, Goodale MA (2008) Two visual systems re-viewed. Neuropsychologia 46:774-785. CrossRef Medline

Missler M, Wolff A, Merker HJ, Wolff JR (1993) Pre- and postnatal development of the primary visual cortex of the common marmoset. II. Formation, remodelling, and elimination of synapses as overlapping processes. J Comp Neurol 333:53-67. CrossRef Medline

Movshon JA, Rust NC, Kohn A, Kiorpes L, Hawken MJ (2004) Receptivefield properties of MT neurons in infant macaques. Perception 33 ECVP Abstract Supplement.

Nassi JJ, Callaway EM (2006) Multiple circuits relaying primate parallel visual pathways to the middle temporal area. J Neurosci 26:1278912798. CrossRef Medline

O'Brien BJ, Abel PL, Olavarria JF (2001) The retinal input to calbindinD28k-defined subdivisions in macaque inferior pulvinar. Neurosci Lett 312:145-148. CrossRef Medline

Purushothaman G, Marion R, Li K, Casagrande VA (2012) Gating and control of primary visual cortex by pulvinar. Nat Neurosci 15:905-912. CrossRef Medline

Robinson SR, Dreher B (1990) The visual pathways of eutherian mammals and marsupials develop according to a common timetable. Brain Behav Evol 36:177-195. CrossRef Medline

Rockland KS (1989) Bistratified distribution of terminal arbors of individual axons projecting from area V1 to middle temporal area (MT) in the macaque monkey. Vis Neurosci 3:155-170. CrossRef Medline

Rockland KS (1995) Morphology of individual axons projecting from area V2 to MT in the macaque. J Comp Neurol 355:15-26. CrossRef Medline

Rockland KS, Andresen J, Cowie RJ, Robinson DL (1999) Single axon analysis of pulvinocortical connections to several visual areas in the macaque. J Comp Neurol 406:221-250. CrossRef Medline 
Sherman SM, Guillery RW (2011) Distinct functions for direct and transthalamic corticocortical connections. J Neurophysiol 106:1068-1077. CrossRef Medline

Shipp S, Zeki S (1989) The organization of connections between areas V5 and V1 in macaque monkey visual cortex. Eur J Neurosci 1:309-332. CrossRef Medline

Sia Y, Bourne JA (2008) The rat temporal association cortical area 2 (Te2) comprises two subdivisions that are visually responsive and develop independently. Neuroscience 156:118-128. CrossRef Medline

Sincich LC, Park KF, Wohlgemuth MJ, Horton JC (2004) Bypassing V1: a direct geniculate input to area MT. Nat Neurosci 7:1123-1128. CrossRef Medline

Spatz WB (1975) Thalamic and other subcortical projections to area MT (visual area of superior temporal sulcus) in the marmoset Callithrix jacchus. Brain Res 99:129-134. CrossRef Medline

Trojanowski JQ, Jacobson S (1976) Areal and laminar distribution of some pulvinar cortical efferents in rhesus monkey. J Comp Neurol 169:371391. CrossRef Medline
Ungerleider LG, Desimone R (1986) Cortical connections of visual area MT in the macaque. J Comp Neurol 248:190-222. CrossRef Medline

Ungerleider LG, Mishkin M (1982) Two cortical visual systems. In: Analysis of visual behaviour (Ingle JD, Goodale MA, Mansfield RJW, eds), pp 549-586. Cambridge, MA: MIT.

Warner CE, Goldshmit Y, Bourne JA (2010) Retinal afferents synapse with relay cells targeting the middle temporal area in the pulvinar and lateral geniculate nuclei. Front Neuroanat 4:8. CrossRef Medline

Wattam-Bell J, Birtles D, Nyström P, von Hofsten C, Rosander K, Anker S, Atkinson J, Braddick O (2010) Reorganization of global form and motion processing during human visual development. Curr Biol 20: 411-415. CrossRef Medline

Weller RE, Wall JT, Kaas JH (1984) Cortical connections of the middle temporal visual area (MT) and the superior temporal cortex in owl monkeys. J Comp Neurol 228:81-104. CrossRef Medline

Zeki SM (1974) Functional organization of a visual area in the posterior bank of the superior temporal sulcus of the rhesus monkey. J Physiol 236:549-573. Medline 